\title{
Quantitative Assessment of Medical Waste Management in Hamad Medical Corporation-Qatar
}

\author{
Huda Al Naemi'1,2, Kingsley Izuka1, Catherine Edquibal'1, Noof Al-Korbi', \\ Noora Al Kuwari1, Maryam Al Homaid1 \\ ${ }^{1}$ Occupational Health \& Safety, Hamad Medical Corporation, Doha, Qatar \\ ${ }^{2}$ Weill Cornell Medicine, Doha, Qatar \\ Email: malhomaid1@hamad.qa
}

How to cite this paper: $\mathrm{Al} \mathrm{Naemi,} \mathrm{H}$. Izuka, K., Edquibal, C., Al-Korbi, N., Al Kuwari, N. and Al Homaid, M. (2021) Quantitative Assessment of Medical Waste Management in Hamad Medical Corporation-Qatar. Occupational Diseases and Environmental Medicine, 9, 112-126. https://doi.org/10.4236/odem.2021.93009

Received: May 5, 2021

Accepted: June 18, 2021

Published: June 21, 2021

Copyright $\odot 2021$ by author(s) and Scientific Research Publishing Inc. This work is licensed under the Creative Commons Attribution International License (CC BY 4.0).

http://creativecommons.org/licenses/by/4.0/

\begin{abstract}
A proper waste management system is very important in healthcare facilities because the overall benefit outweighs the cost. In the healthcare sector, hazardous health care waste (HHCW) consists of wastes that are potentially contaminated by dangerous agents. Identification and segregation of HHCW is harbinger for its proper management. The quantitative analysis study on HHCW had not been done in Qatar government hospitals. This study quantitatively analyzed the current practice for HHCW management in Hamad Medical Corporation (HMC), Qatar. The objective of this study is to provide a first comprehensive assessment of hazardous healthcare waste managements in Qatar and offers an opportunity to improve existing practice. This is a retrospective survey study carried out on secondary data collected from the department of occupational health and safety (OHS), HMC. OHS department collects and keeps records of hazardous wastes produced by HMC. Data on the HMC hospitals' characteristics from 2017 to 2019 were retrieved from Planning and Statistics Authority's website. World Health Organization (WHO) formula for calculating HHCW generation rate was used to calculate the rate for HMC. Data analysis results show a steady increase in HHCW generation rate in $\mathrm{HMC}$, the generation rate was $2.6 \mathrm{Kg} /$ patient bed/day, 2.8 $\mathrm{Kg} /$ patient bed/day and $3.1 \mathrm{Kg} /$ patient bed/day for the years 2017, 2018 and 2019 respectively. There were also significant variations in HHCW generation rates between hospitals. The highest generation rate was $4.64 \mathrm{Kg} / \mathrm{patient}$ bed/day recorded for AWH and the lowest was $0.2 \mathrm{Kg} / \mathrm{patient}$ bed/day recorded for mental health and both hospitals contributing $23.18 \%$ and $0.29 \%$ respectively of HHCW in HMC.
\end{abstract}




\section{Keywords}

Hazardous Healthcare Waste, Quantitative Analysis, Generation Rate, World Health Organization, Hamad Medical Corporation Qatar

\section{Introduction}

Global campaign for proper waste management is critical for the conservation of our environment and public health promotion. The environmental, health and economic benefits of proper management and control of healthcare wastes had been reported by several authors [1] [2] [3]. The concept of waste has different meanings to different individuals and nations. However, generally wastes are categorized into two broad groups: hazardous and non-hazardous wastes [4] [5] [6]. In the healthcare or medical sector, hazardous wastes consist of wastes that are potentially contaminated by biological, chemical, or physical agents that possess health or environmental hazards [7] [8] [9] [10]. Several studies had suggested that a typical general hospital in any country worldwide produces about $80 \%$ non-hazardous and $20 \%$ hazardous wastes. The hazardous group is composed of about $15 \%$ pathological waste, $3 \%$ chemical waste, $1 \%$ sharp waste, and less than $1 \%$ special waste such as cytotoxic, broken thermometers, pressurized containers, radioactive waste and used batteries [9] [11] [12].

These reported proportions are not far from World Health Organization (WHO) estimates for hazardous and non-hazardous healthcare wastes. WHO estimated that each country globally has a generation rate of healthcare waste ranging from 0.5 to $3.0 \mathrm{Kg} / \mathrm{bed} /$ day [7] [8] [13]. According to WHO (2014) report, high-income countries on average may generate up to $0.5 \mathrm{~kg}$ of hazardous medical waste per hospital bed per day whereas low-income countries generate on average $0.2 \mathrm{~kg}$ per hospital bed per day. However, this quantity can vary in the developing or low-income countries due to lack of proper waste identification and segregation practices. The volume and composition of the waste stream produced by healthcare depend on many factors which include the specialties and size of the hospitals, the segregation process applied, and available laws and policies [9] [11] [12] [14].

Approximately $90 \%$ of hazardous healthcare waste is infectious by nature. Infectious healthcare wastes are wastes that may be produced during the diagnosis, treatment or immunization of humans or animals, or during the research activities pertaining thereto, or in the production or testing of biologicals [15] [16] [17] [18]. Hazardous medical wastes are unique forms of wastes that require absolute care and management because of its origin and negative public perceptions about its characteristics. This type of waste needs a proper treatment to avoid the risk of presence of pathogens in substantial quantities that may lead to the spread of diseases through air, water, and contact [16] [17] [19]. Globally, different management and treatment methods for infectious healthcare waste 
have been developed and applied across different countries [16]. Waste identification, segregation, packing, and decontamination are among common practices worldwide however, significant variations in process, magnitude and scope exist. Among observed decontamination methods for treating infectious medical waste includes thermal incineration, steam sterilization, microwaving, irradiation, and chemical disinfection [9] [11] [12].

Identification and segregation of medical waste is a harbinger for its proper management. These two processes are directly linked to infectious waste magnitude within a hospital setting [13]. Poor medical waste identification and segregation often result in an increase in hazardous waste generation per patient bed per day. This in turn results in a significant increase in the demand for waste management resources [16] [17]. World Health Organization (WHO) had suggested a quantitative analysis of healthcare waste among healthcare establishments. This analysis provides an ideal method to determine waste generation rate and waste assessment process that offer an opportunity to improve the existing practices. Medical waste has not received appropriate consideration in developing countries and some Middle East countries [1] [3] [7] [13].

In Qatar, the quantity of healthcare waste is rapidly increasing as a result of the rapid establishment of numerous medical care facilities in the country in the last few years. In recent years growing interest and implementation of healthcare waste management systems have been contributing to the protection of public health in Qatar. The healthcare waste management system emphasizes the need to train healthcare workers on proper handing, segregation, storage, and disposal of healthcare waste in order to prevent the health risk to the individual, general population and the environment [1] [10].

Hamad Medical Corporation (HMC) is the largest healthcare provider in Qatar. The organization composed of 14 Joint Commission International (JCI) accredited tertiary hospitals including the country's ambulance service. Many more health facilities under HMC are waiting commissioning. HMC healthcare waste management system includes a hazardous materials and waste management program. The objective of the program is to achieve excellent waste management through proper waste identification, segregation, packaging, waste tracking system and proper treatment and safe final disposal. The hazardous materials and waste management program was developed in response to the Guideline of Health Care Waste Management issued by Council of Ministers Qatar.

Several researches on healthcare waste management are available in different countries worldwide. However, no such study on healthcare waste had been carried out in any of the tertiary hospitals in Qatar. The need for empirical analysis of healthcare waste generation among HMC hospitals is inevitable. The objective of this study is to quantitatively analyze the current practices in healthcare waste management among HMC hospitals in Qatar. The study focuses mainly on hazardous (infectious) waste magnitude and generation rate. The waste generation rate will be portrayed through active bed capacity within each hospital and as 
collectively. Secondly, results from this study will be compared to WHO healthcare waste estimate reports and estimate reports from other countries especially countries belonging to Gulf Cooperation Council (GCC).

\section{Methods}

This study was carried out in ten (10) governmental tertiary hospitals under Hamad Medical Corporation (HMC) in Qatar. The hospitals are Al Khor Hospital (AKH), Al Wakra Hospital (AWH), Communicable Disease Center (CDC), Hamad General Hospital (HGH), Hearth Hospital (HH), Mental Health Services (MHS), National Center for Cancer Care \& Research (NCCCR), Rumailah Hospital (RH), The Cuban Hospital (TCH), and Women's Wellness \& Research Center (WWRC). The characteristics and description of the hospitals are shown in Table 1(a) and Table $1(\mathrm{~b})$ respectively. This includes the number of active beds, number of Units/Departments, and number of employees in each hospital for 2017 to 2019.

The Healthcare Wastes (HCW) generated from these hospitals are centrally managed by two corporate departments-Hospitality Department and Occupational Health and Safety (OHS) Department. The Hospitality Department is responsible for the collection, packaging, labelling, and transportation of all HCW generated from every of the hospitals. The non-hazardous HCW is transported to government landfill for possible recycling and final disposal by the Ministry of Municipality and Environment, Qatar.

The Hazardous Healthcare Waste (HHCW) is transported to Waste Treatment Plant (WTP) controlled by Environmental Safety Section of OHS Department (ESS-OHS). At the WTP, the wastes are measured and the weight of different categories of waste is recorded. ESS-OHS operates four (4) medical WTP in Qatar. The WTP's treatment technology uses autoclave with integrated shredding which decontaminate and shred the infectious HHCW. Other HHCW are treated off-site by incineration provided by licensed private company.

\section{Data Collection}

Environmental Safety Section of Occupational Health and Safety Department (ESS-OHS) collects and maintained records of hazardous healthcare wastes (HHCW) generated from individual hospitals of HMC. 2017, 2018, and 2019 wastes records for individual hospitals were extracted from the master record of HHCW maintained by ESS-OHS. The wastes data collected for individual hospital includes infectious wastes, sharp wastes, pathological wastes, and cytotoxic wastes (Table 2).

The collected wastes data were organized using Microsoft Office Excel and the total annual wastes generated were calculated for 2017, 2018, and 2019. The HHCW generation rate (kilogram of wastes per patient bed per day) was calculated using the modified World Health Organization formula: HHCW generation rate is equals to total weight of HHCW in kilograms per year divided by the product of number of days in a year and number of active beds. 
Table 1. (a) Characteristics of HMC hospitals; (b) Brief description of studied HMC hospitals.

(a)

\begin{tabular}{|c|c|c|c|c|}
\hline \multirow[b]{2}{*}{ Hospital } & \multirow[b]{2}{*}{ Year } & \multicolumn{3}{|c|}{ Characteristics of Hospital } \\
\hline & & $\begin{array}{l}\text { Number of } \\
\text { Active Beds }\end{array}$ & $\begin{array}{c}\text { Number of } \\
\text { Units/Departments }\end{array}$ & $\begin{array}{l}\text { Number of } \\
\text { Employees }\end{array}$ \\
\hline \multirow{3}{*}{$\begin{array}{c}\text { Al Khor Hospital } \\
\text { (AKH) }\end{array}$} & 2017 & 113 & & 980 \\
\hline & 2018 & 113 & 35 & 980 \\
\hline & 2019 & 172 & & 1470 \\
\hline \multirow{3}{*}{$\begin{array}{c}\text { Al Wakra Hospital } \\
\text { (AWH) }\end{array}$} & 2017 & 326 & & 3337 \\
\hline & 2018 & 326 & 70 & 2351 \\
\hline & 2019 & 295 & & 2518 \\
\hline \multirow{3}{*}{$\begin{array}{l}\text { Communicable Disease Center } \\
\text { (CDC) }\end{array}$} & 2017 & 65 & & 228 \\
\hline & 2018 & 65 & 18 & 281 \\
\hline & 2019 & 65 & & 303 \\
\hline \multirow{3}{*}{$\begin{array}{l}\text { Hamad General Hospital } \\
\text { (HGH) }\end{array}$} & 2017 & 678 & & 5298 \\
\hline & 2018 & 663 & 73 & 6030 \\
\hline & 2019 & 678 & & 6120 \\
\hline \multirow{3}{*}{$\begin{array}{l}\text { Heart Hospital } \\
(\mathrm{HH})\end{array}$} & 2017 & 116 & & 1111 \\
\hline & 2018 & 114 & 37 & 1098 \\
\hline & 2019 & 116 & & 1282 \\
\hline \multirow{3}{*}{$\begin{array}{c}\text { Mental Health Services } \\
\text { (MHS) }\end{array}$} & 2017 & 77 & & 399 \\
\hline & 2018 & 77 & 12 & 470 \\
\hline & 2019 & 116 & & 560 \\
\hline \multirow{3}{*}{$\begin{array}{l}\text { National Center for Cancer } \\
\text { Care \& Research (NCCCR) }\end{array}$} & 2017 & 65 & & 659 \\
\hline & 2018 & 61 & 30 & 707 \\
\hline & 2019 & 60 & & 739 \\
\hline \multirow{3}{*}{$\begin{array}{l}\text { Rumailah Hospital } \\
\text { (RH) }\end{array}$} & 2017 & 294 & & 1795 \\
\hline & 2018 & 377 & 40 & 1723 \\
\hline & 2019 & 344 & & 1644 \\
\hline \multirow{3}{*}{$\begin{array}{l}\text { The Cuban Hospital } \\
\text { (TCH) }\end{array}$} & 2017 & 72 & & 472 \\
\hline & 2018 & 72 & 32 & 497 \\
\hline & 2019 & 72 & & 665 \\
\hline Women's Hospital (2017) & 2017 & 354 & & 1600 \\
\hline $\begin{array}{c}\text { Women's Wellness and } \\
\text { Research Center (2018-2019) }\end{array}$ & 2018 & 339 & 39 & 1800 \\
\hline (WWRC) & 2019 & 340 & & 1938 \\
\hline
\end{tabular}

(b)

\begin{tabular}{cl}
\hline \multicolumn{1}{c}{ Hospital } & \multicolumn{1}{c}{ Description } \\
\hline & Al Khor Hospital is a general hospital and one of HMC's community \\
hospitals in the northern region of Qatar. The hospital hosts an \\
Al Khor Hospital \\
Antenatal and Postnatal Exercise Center, as well as a Breastfeeding \\
Resource Center. It also has Emergency Department, Intensive Care \\
& Unit, Pediatrics, Obstetrics and Gynecology, Radiology, Dermatology, \\
& Psychiatry and Surgery Departments.
\end{tabular}


Al Wakra Hospital is a general hospital in the south of Qatar serving the towns of Al Wakra and Mesaieed. The hospital offers range of general hospital diagnostic and treatment services for outpatients, inpatients,

Al Wakra Hospital (AWH) and day care patients. It has capacity for general, acute patients, critical care, high dependency, observation/day beds, and burn patients of all ages. It has the largest hospital building in Qatar with its own Central Sterile Services Department, Mortuary, Laboratories, Laundry, Supply Chain Warehouse, Engineering Services, and Waste Treatment Plant.

The Communicable Disease Center is a specialist tertiary center which has 65 single-isolation rooms with outpatient services that support and

Communicable Disease Center (CDC) specialized in tuberculosis (TB) and other infectious disease management. It offers diagnosis, treatment, and prevention of infectious disease as well as education and research.

Hamad General Hospital is a general hospital located in Doha which offers wide range of medical care and clinical services including emergency medicine, pediatrics, critical care, specialized and sub-specialized surgeries, specialized medicine, laboratory medicine, diagnostic and adult rehabilitation services. It also has Mortuary, Central Sterile Services Department, Laboratories, Supply Chain Warehouse, Engineering Services, Laundry, and Waste Treatment Plant.

Hamad General Hospital (HGH)

Heart Hospital is a specialist hospital for cardiology and cardiothoracic surgery patients. It offers specialized care and cardiology services for patients including cardiac and thoracic surgery, open heart surgery and

Heart Hospital $(\mathrm{HH})$ emergency cardiac services. The hospital has its own clinical imaging department delivering cardiac computed tomography (CT), cardiac isotope studies and a full range of diagnostic procedures. It also has dedicated nephrologists and a dialysis service.

Mental Health Service provides specialized mental health care and treatment to a range of acute and community-based services which includes consultation/liaison, inpatients, and emergency services. It has outpatient clinics for adults, adolescents, and children. They also provide therapies such as psychology and psychotherapy.

The National Center for Cancer Care and Research is the primary cancer hospital in Qatar. It takes care of patients who require constant treatment such as chemotherapy and radiotherapy, treats blood conditions, it also provides Bone Marrow transplant. The facility also offers services such as urgent care, hematology, oncology, and palliative care. The hospital houses Positron Emission Tomography-Computed Tomography (PET CT) scanner to detect and monitor cancers to improve patient outcomes.

National Center for

Cancer Care \& Research (NCCCR)

Rumailah Hospital is a multi-specialty hospital that offers specialized

Rumailah Hospital $(\mathrm{RH})$ nose, throat (ENT), ophthalmology and plastic surgery, physiotherapy, geriatric, and long term care.

The Cuban Hospital, located in Dukhan, Qatar. The hospital offers

The Cuban Hospital (TCH) specialized care and services including dentistry, gynecology, diabetes, dermatology, ENT, and audiology, emergency services for children and adults and general medicine.

Women's Wellness and Research Center is the country's largest tertiary hospital dedicated to women's health. It offers expertise in areas including antenatal, gynecological, and neonatal care, with a wide range of clinical services for inpatients, outpatients, expectant parents, and new parents. 
Table 2. HMC Hospitals Hazardous Healthcare Wastes (HHCW) generation from 2017-2019.

\begin{tabular}{|c|c|c|c|c|}
\hline \multirow{2}{*}{ HOSPITALS } & \multirow{2}{*}{ TYPE OF WASTES } & \multicolumn{3}{|c|}{ YEAR/WEIGHT (Kg) } \\
\hline & & 2017 & 2018 & 2019 \\
\hline \multirow{5}{*}{$\begin{array}{l}\text { Al Khor Hospital } \\
(\mathrm{AKH})\end{array}$} & Infectious Wastes & 83,346 & 99,858 & 107,969 \\
\hline & Sharp Wastes & 31,188 & 18,326 & 13,146 \\
\hline & Cytotoxic Waste & 2 & 13 & 0 \\
\hline & Pathological Wastes & 859 & 771 & 837 \\
\hline & TOTAL & 115,395 & 118,968 & 121,951 \\
\hline \multirow{5}{*}{$\begin{array}{c}\text { Al Wakra Hospital } \\
\text { (AWH) }\end{array}$} & Infectious Wastes & 414,593 & 529,608 & 604,050 \\
\hline & Sharp Wastes & 15,912 & 15,505 & 15,860 \\
\hline & Pathological Waste & 3332 & 2512 & 2235 \\
\hline & Cytotoxic Waste & 226 & 47 & 81 \\
\hline & TOTAL & 434,064 & 547,672 & 622,226 \\
\hline \multirow{4}{*}{$\begin{array}{l}\text { Communicable Disease Center } \\
\text { (CDC) }\end{array}$} & Infectious Wastes & 53,379 & 60,232 & 65,180 \\
\hline & Sharp Wastes & 31 & 2815 & 3532 \\
\hline & Cytotoxic Waste & 0 & 8 & 0 \\
\hline & TOTAL & 53,410 & 63,055 & 68,712 \\
\hline \multirow{5}{*}{$\begin{array}{l}\text { Hamad General Hospital } \\
\text { (HGH) }\end{array}$} & Infectious Wastes & 602,782 & 664,946 & 739,570 \\
\hline & Sharp Wastes & 129,792 & 65,930 & 70,033 \\
\hline & Pathological Waste & 1626 & 8979 & 13,586 \\
\hline & Cytotoxic Waste & 736 & 811 & 285 \\
\hline & TOTAL & 734,937 & 686,770 & 823,474 \\
\hline \multirow{4}{*}{$\begin{array}{l}\text { Heart Hospital } \\
\text { (HH) }\end{array}$} & Infectious Waste & 54,305 & 68,259 & 79,332 \\
\hline & Sharp Wastes & 11,155 & 9705 & 11,876 \\
\hline & Cytotoxic Waste & 0 & 3 & 0 \\
\hline & TOTAL & 65,460 & 77,966 & 91,208 \\
\hline \multirow{3}{*}{$\begin{array}{l}\text { Mental Health Services } \\
\text { (MHS) }\end{array}$} & Infectious Wastes & 5281 & 5775 & 5908 \\
\hline & Sharp Wastes & 1184 & 1039 & 751 \\
\hline & TOTAL & 6,465 & 6,814 & 6,658 \\
\hline \multirow{4}{*}{$\begin{array}{l}\text { National Center for Cancer } \\
\text { Care and Research } \\
\text { (NCCCR) }\end{array}$} & Infectious Wastes & 55,190 & 51,302 & 65,112 \\
\hline & Sharp Wastes & 11,332 & 8219 & 9500 \\
\hline & Cytotoxic Waste & 6311 & 6772 & 7777 \\
\hline & TOTAL & 72,833 & 66,293 & 82,389 \\
\hline \multirow{3}{*}{$\begin{array}{l}\text { Rumailah Hospital } \\
\text { (RH) }\end{array}$} & Infectious Wastes & 280,627 & 345,971 & 308,021 \\
\hline & Sharp Wastes & 14,573 & 15,705 & 17,899 \\
\hline & TOTAL & 295,200 & 361,676 & 325,920 \\
\hline
\end{tabular}




\begin{tabular}{ccccc}
\hline & Infectious Waste & 73,273 & 79,587 & 80,355 \\
The Cuban Hospital & Sharp Wastes & 3194 & 1664 & 4308 \\
(TCH) & Pathological Waste & 720 & 867 & 709 \\
& TOTAL & $\mathbf{7 7 , 1 8 6}$ & $\mathbf{8 2 , 1 1 8}$ & $\mathbf{8 5 , 3 7 1}$ \\
\hline $\begin{array}{c}\text { Women's Hospital (2017) } \\
\text { Women's Wellness and } \\
\text { Research Center } \\
\text { (2018-2019) } \\
\text { (WWRC) }\end{array}$ & Shfectious Wastes & 184,740 & 252,069 & 320,774 \\
& Pathological Waste & 10,748 & 10,624 & 11,336 \\
& Cytotoxic Waste & 65 & 114 & 117 \\
& TOTAL & $\mathbf{2 0 6 , 5 3 2}$ & $\mathbf{2 7 5 , 7 3 1}$ & $\mathbf{3 4 4 , 7 5 5}$ \\
\hline
\end{tabular}

$$
\text { HHCW generation rate }=\frac{\text { Total HHCW weight } \mathrm{kg} / \text { year }}{(365.24 \text { days })(\text { number of active beds })}
$$

Finally, the combined data from each of the ten facilities was used to estimate the average HHCW generation rate for HMC in 2017 to 2019.

\section{Results and Discussion}

The data findings from the HMC demonstrates that from the ten samples of the different healthcare facilities, HGH had the largest number of active beds between 2017to 2019 with 678, 663 and 678 respectively (Table 1(a)). This means that HGH served the majority of patients within the HMC. Chances were very high that most of the patients came from other branches to HGH for treatment. However, the facility that had the lowest number of active beds was the NCCCR, which had approximately, 65, 61, and 60 between 2017 to 2019 sequentially, which means that it served the lowest number of inpatients (Table 1(a)). The difference between the two facilities within the same period was 613,601 , and 613 correspondingly. The variation was quite large as it was almost ten times despite the fact that the number of units differed with around half, where HGH had 73 units while the NCCCR had 30 units, which means that they differed with 43 divisions (Table 1(a)). Furthermore, HGH had 5298, 6030 and 6120 employees between 2017 to 2019 respectively while NCCCR had 659, 707 and 739 (Table 1(a)).

The HHCW that have been collected from HMC waste treatment plant represented that HGH had the highest amount of wastes collection within the three years period of 2017 to 2019 respective. The quantities were 734,936.65 kgs, $686,770.10 \mathrm{kgs}$ and $821,251.20$ respectively, which signified that a reduction in the number of active bed contributed to the decline of the waste quantity and that an increase in the number of active beds led to the increase of the number of hazardous waste (Table 2). Farther, the infectious wastes productions were the most maximum, while the cytotoxic wastes were the most insignificant. This aspect was clear that the facility had a high number of infections wastes; thus, individual in such places were highly vulnerable to such problems. On the other hand, MHS had the lowest number of the medical waste generations, which was 
6464.60, 6813.90 and 6658.20 between 2017 to 2019, respectively (Table 2). The infectious wastes were $5281.00,5774.50$ and 5907.60 between the three years period (Table 2).

The HMC yearly average HHCW production rate showed that creation of hazardous wastes within the 10 facilities was high in 2019 with approximately 3.1 while in 2018, it was 2.8 and the lowest in 2017 that had 2.6. From the data shown in Figure 1, it was apparent that 2017 had the lowest numbers of patients who visited the different health care facilities while the number increased in 2018 with approximately 20\%. Additionally, in 2019 the rate improved by $30 \%$ which illustrated a further increase in the number of people who attended the hospital. This aspect means that between 2017 and 2019, the rate HHCW contrasted by $50 \%$. From the analysis, the health status in the society continued to decline within the same period causing more hospital admission rates forcing doctors to apply more treatment supplies. This indicates that the society suffered higher infection rates in 2019 compared to 2017 and 2018.

Figure 2 demonstrates the HHCW generation in the number of patient attendances per month to the several HMC facilities from the year 2017 to 2019 . The number active beds in HMC facilities in 2017 rose steadily to the highest level of 2260 compared to 2018 whereby it posed a significant reduction of $15 \%$. This indicated that the prevalence of diseases in the year 2017. HGH recorded

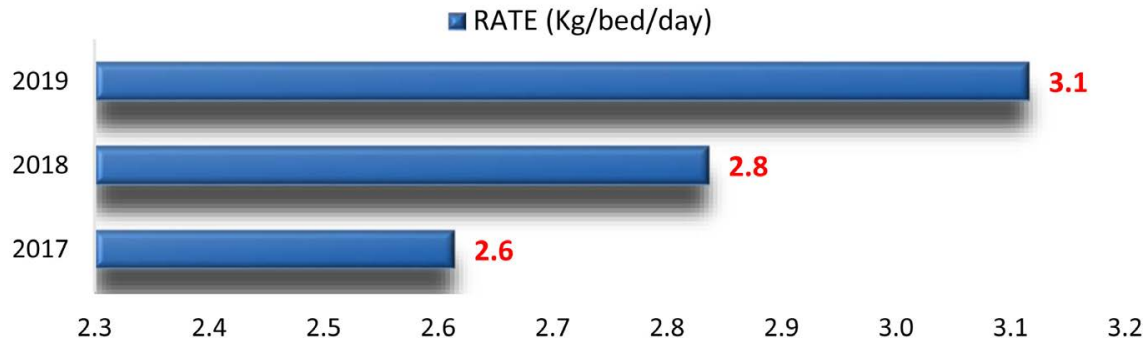

Figure 1. HMC yearly average hazardous healthcare waste generation rate.

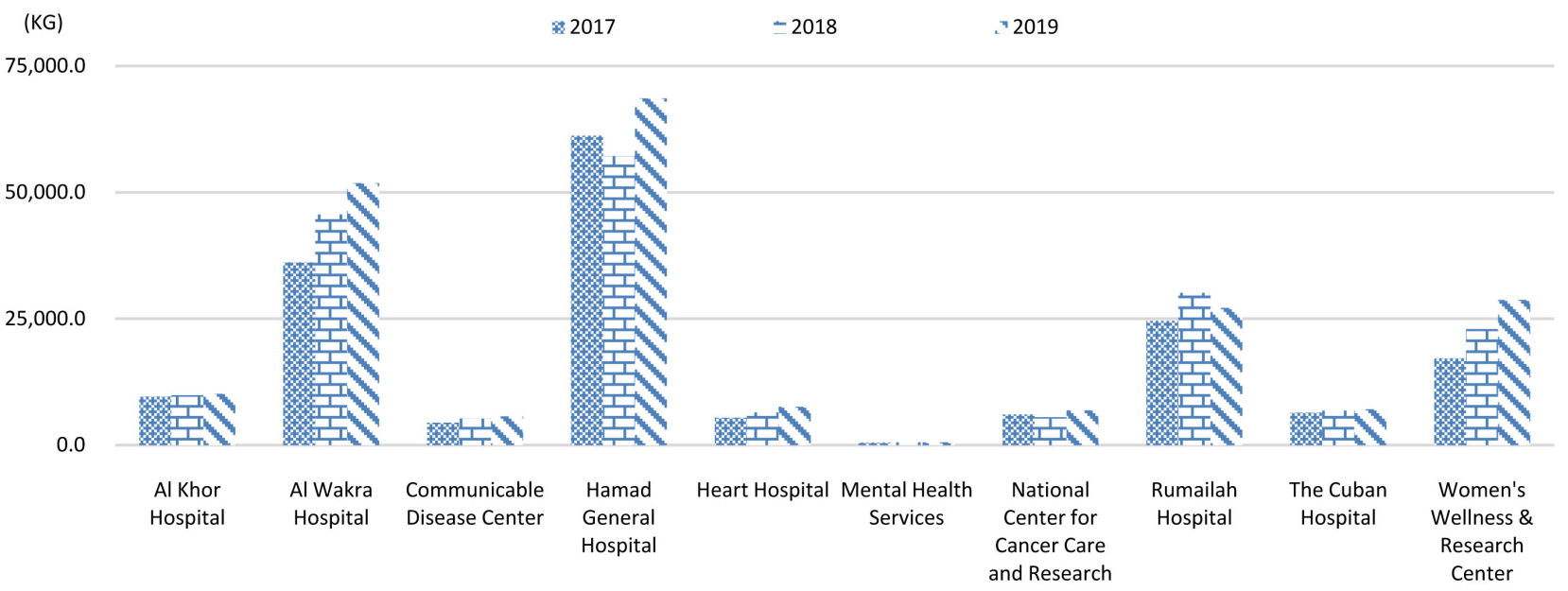

Figure 2. HMC monthly average hazardous healthcare waste generation from 2017 to 2019. 
the highest number of patients and active beds throughout the month while Mental Services facility recorded the least cases of patient and active beds. The HGH amounted to almost $60 \%$ of the prevalence cases as indicated on the graph while other facilities recorded a minimum of $40 \%$ of the cases. However, the analysis provided an overview of the HHCW generation on patient attendance per month. From this observation, the prevalence of diseases mostly occurs on the spring. This is due to cold weather experienced during the season. In addition, the number of employees' recruitment in HMC facilities declined by $5 \%$ in 2019 due to less infections and patient attendance to most of its facilities.

Figure 3 demonstrates HHCW percentage contribution per HMC facility from 2017 to 2019. HGH had the highest percentage of 32.4\%, and MHS had the lowest value of $0.3 \%$. The difference between the two facilities was $32.1 \%$, which was quite huge. From these data, it is clear that the ratio between the volumes of the HHCW at HGH related to the number of the active beds that was quite high in comparison with other healthcare facilities thus making it to have the highest percentage. Another factor that might have caused this scenario is the generation of high amounts of HHCW that was inversely proportional to the number of active beds in different units of the HGH. On the other hand, the MHS facility had few HHCW compared to other hospitals and thus providing the least amount of HHCW percentage.

In Table 3, the information on the ranking based on number of beds, the percentage of HHCW generation, rate of every patient occupying each bed illustrated unique findings. For example, the quantity of the active beds was high at the HGH, which had a value of 2019 active beds, while the lowest was NCCCR that had 186 active beds. This aspect was clear that HGH served the highest number of patients while NCCCR attended the lowest number between 2017 to 2019. Additionally, using the percentage of the HHCW contribution, HGH was still heading with $32.43 \%$, which showed that the HGH had the highest number of patients and hence generated the highest quantities of HHCW. In contrast, MHS had the lowest rank of 10 . These results indicate that the facility used a few

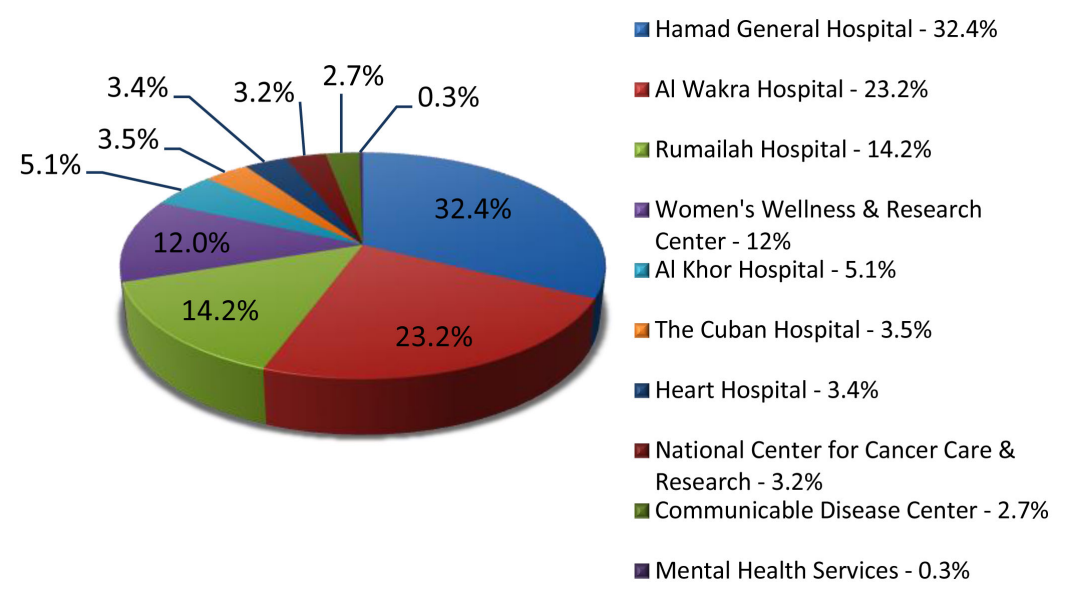

Figure 3. HHCW percentage contribution per HMC hospital from 2017 to 2019. 
Table 3. HMC hospitals rank order based on number of active beds, percentage (\%) HHCW contribution and HHCW generation rate from 2017 to 2019.

\begin{tabular}{|c|c|c|c|c|c|c|}
\hline HOSPITAL & $\begin{array}{l}\text { Total No. } \\
\text { of Active } \\
\text { Beds }\end{array}$ & Rank & $\begin{array}{c}\text { \% HHCW } \\
\text { Contribution } \\
(\mathrm{Kg})\end{array}$ & Rank & $\begin{array}{c}\text { HHCW } \\
\text { Generation Rate } \\
\text { (Kg/patient bed/day) }\end{array}$ & Rank \\
\hline $\begin{array}{l}\text { Hamad General } \\
\text { Hospital }\end{array}$ & 2019 & 1 & $32.43 \%$ & 1 & 3.04 & 4 \\
\hline $\begin{array}{l}\text { Women's Wellness } \\
\text { \& Research Center }\end{array}$ & 1033 & 2 & $11.95 \%$ & 4 & 2.19 & 8 \\
\hline Rumailah Hospital & 1015 & 3 & $14.20 \%$ & 3 & 2.65 & 5 \\
\hline Al Wakra Hospital & 947 & 4 & $23.18 \%$ & 2 & 4.64 & 1 \\
\hline Al Khor Hospital & 398 & 5 & $5.15 \%$ & 5 & 2.45 & 7 \\
\hline Heart Hospital & 346 & 6 & $3.39 \%$ & 7 & 1.86 & 9 \\
\hline $\begin{array}{c}\text { Mental } \\
\text { Health Services }\end{array}$ & 270 & 7 & $0.29 \%$ & 10 & 0.20 & 10 \\
\hline The Cuban Hospital & 216 & 8 & $3.54 \%$ & 6 & 3.10 & 3 \\
\hline $\begin{array}{l}\text { Communicable } \\
\text { Disease Center }\end{array}$ & 195 & 9 & $2.68 \%$ & 9 & 2.60 & 6 \\
\hline $\begin{array}{l}\text { National Center } \\
\text { for Cancer Care } \\
\text { \& Research }\end{array}$ & 186 & 10 & $3.20 \%$ & 8 & 3.26 & 2 \\
\hline
\end{tabular}

quantities of HHCW as they protected the victims of this facility from interfering with the HHCW, which contributes to greater challenges within the hospital. Additionally, the HHCW accumulation rate per individual's bed was highest at AWH, which had $4.64 \%$, while the lowest was MHS, which had $0.20 \%$.

The graph in Figure 4 illustrates the average HHCW generation per patient bed per hospital from 2017 to 2019. Based on the analysis of the graph, HGH produced the highest volume with approximately 2,245,181 cases while the least was MHS, which it depicted 19,937 cases. HGH contributed to $32.43 \%$ of the total number of beds from 2017 to 2019 while MHS provided the minimum percentage of $0.29 \%$ to the total number of beds. However, the analysis interpretation brought into account that HGH had the highest medical waste that approximates to almost $58 \%$ of the total waste in HMC hospitals. It has an average of 3.04 in $\mathrm{kg}$ per bed per day, which is slightly less to AWH that constitutes to 4.64. Although $\mathrm{HGH}$ posed a higher medical waste than $\mathrm{AWH}$, the rate of the AWH in HHCW generation per patient per bed is slightly higher because it handles chronic patients who might tend to seek medication longer. This analysis creates a great impact in healthcare service delivery to HMC hospitals in a way that it allows proper decision making and enhancing safety and recovery amongst its clients.

The graph in Figure 5 demonstrates the HHCW generation in kgs in different seasons from 2017 to 2019. Based on the analysis, the highest volume of HHCW generations was in 2017 appeared in spring with a total of 540,362.50 kgs, and 


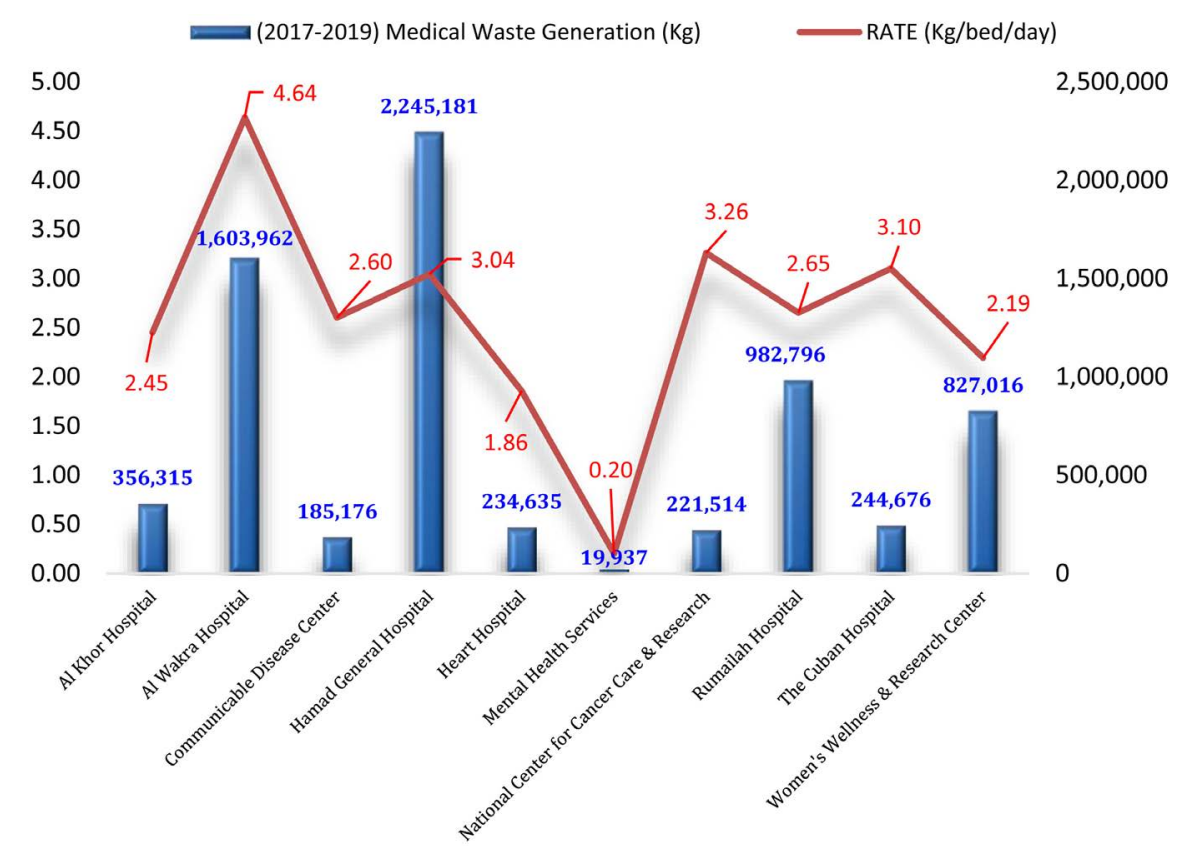

Figure 4. HMC hospitals average HHCW generation rate from 2017 to 2019.

$$
\text { 】2017 ヨ2018 \2019 }
$$

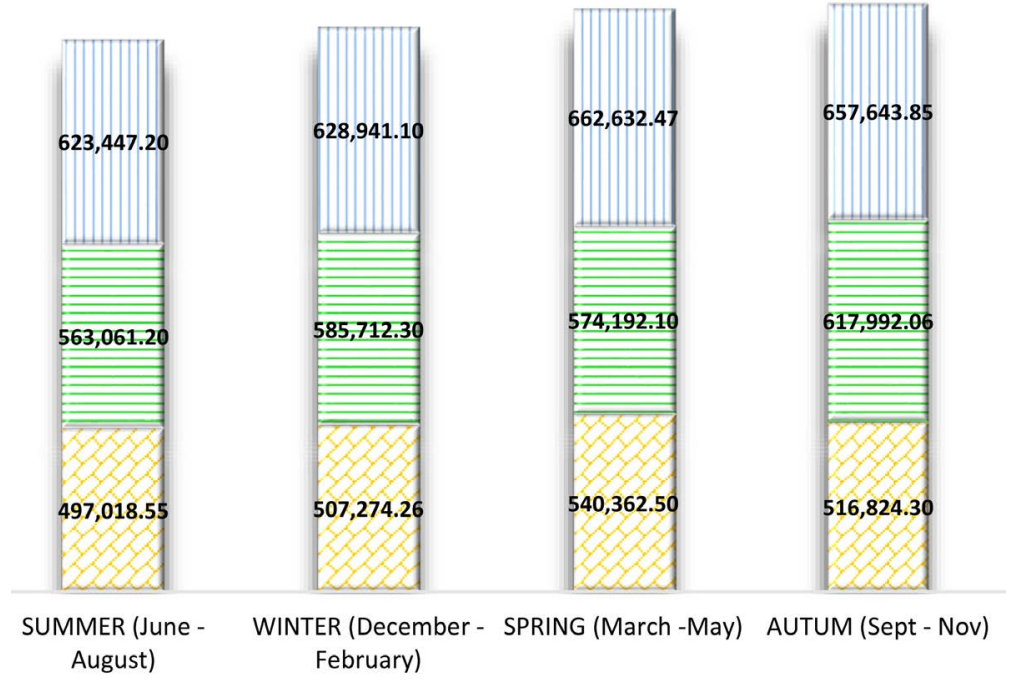

Figure 5. HHCW generation (Kg) per qatar season from 2017-2019.

the lowest in summer with $497,018.55 \mathrm{kgs}$. In 2018 , the most significant quantities occurred in autumn with $617,992.06 \mathrm{kgs}$, while the lowest was $563,061.20$ in summer. Additionally, in 2019 the largest amounts of HHCW were 662,632.47 $\mathrm{kgs}$ in spring and the most lower during this period was $623,447.20 \mathrm{kgs}$ occurred in summer. These results indicate that most people became sick in the autumn season as illustrated in 2017 and 2019, which had the highest quantity of HHCW. However, the overall findings from Figure 5 are that the summer season over the three years experienced the lowest quantities of HHCW generation. This aspect occurs because during this time, the weather is conducive and hence 
hospitals receive reduced numbers of patients, as they don't fall sick regularly. This aspect results in generation fewer amounts of HHCW. Therefore, seasons play a critical role in the determination of the HHCW.

This observed rate corresponds to WHO estimated HHCW generation rate. WHO estimated that each country globally has a generation rate of HHCW ranging from 0.5 to $3.0 \mathrm{Kg} / \mathrm{bed} /$ day [7] [8] [13]. Compared to the results from some other countries in the Middle East, Qatar HHCW generation rate is lower to Iran, Jordan, and Kuwait average HHCW generation rates which were 3.03 $\mathrm{Kg} /$ patient bed/day, $3.44 \mathrm{Kg} /$ patient bed/day and $3.81 \mathrm{Kg} /$ patient bed/day respectively [7] [20] [21]. However, the results from studies in Palestine and Saudi Arabia shows a lower generation rate $0.85 \mathrm{Kg} /$ patient bed/day and 0.51 $\mathrm{Kg} /$ patient bed/day compared to result from Qatar [7]. Studies from Ethiopia and Uganda, two African countries show generation rates of $3.46 \mathrm{Kg} /$ patient bed/day and $0.25 \mathrm{Kg} /$ patient/day respective [22]. Results from all countries worldwide indicated that HHCW generation rates were affected by multiple factors, which include waste identification, segregation, policies, and study duration. Compared to most studies from other countries where study results were gotten from short term HHCW assessment and analysis, this study comprised of a three-year assessment of HHCW and possesses a higher external validity in relation to many studies in other countries were only few healthcare facilities were enrolled for study.

\section{Conclusion}

The result of this empirical analysis of HHCW generated from HMC shows an overall average generation rate value of $2.833 \mathrm{Kg} /$ patient bed/day. The result of this study indicates a moderate HHCW generation rate. Seasons play a critical role in the determination of the HHCW.

\section{Acknowledgements}

The authors would like to sincerely acknowledge the contribution of Environment Safety Section staff (ESS) for their co-operation and help in collecting the data for this paper.

\section{Conflicts of Interest}

The authors declare no conflicts of interest regarding the publication of this paper.

\section{References}

[1] Akbar, E., Nowrouz, P. and Sheikholeslami, S. (2017) Status and Challenges of Medical Waste Management in Hospitals of Iran. Civil Engineering Journal, 3, 741-748.

[2] Yazie, T.D., Tebeje, M.G. and Chufa, K.A. (2019) Healthcare Waste Management Current Status and Potential Challenges in Ethiopia: A Systematic Review. BMC Research Notes, 12, Article No. 285. 
https://bmcresnotes.biomedcentral.com/articles/10.1186/s13104-019-4316-y

[3] Yurtseven, E., Erdogan, M.S., Erginoz, E., Vehid, S., Koksal, S. and Kaypmaz, A. (2010) Quantitative Assessment of Medical Waste Generation in the Hospitals of Istanbul, Turkey. Environmental Engineering and Management Journal, 9, 833-837. https://doi.org/10.30638/eemj.2010.111

[4] Eleyan, D., Al-Khatib, I.A. and Garfield, J. (2013) System Dynamics Model for Hospital Waste Characterization and Generation in Developing Countries. Waste Management \& Research, 31, 986-995. https://doi.org/10.1177/0734242X13490981

[5] Meleko, A., Tesfaye, T. and Henok, A. (2018) Assessment of Healthcare Waste Generation Rate and Its Management System in Health Centers of Bench Maji Zone. Ethiopian Journal of Health Sciences, 28, 125. https://doi.org/10.4314/ejhs.v28i2.4

[6] Ramesh, A. and Thakur, V. (2015) Healthcare Waste Management Research: A Structured Analysis and Review (2005-2014). Waste Management \& Research: The Journal for a Sustainable Circular Economy, 33, 855-870.

[7] Alagha, O., Alomari, A. and Jarrah, N. (2018) Medical Waste Management and Production Rate in the Eastern Province of the Kingdom of Saudi Arabia. Euro-Mediterranean Journal for Environmental Integration, 3, Article No. 35. https://doi.org/10.1007/s41207-018-0078-5

[8] Adu, R.O., Gyasi, S.F., Essumang, D.K. and Otabil, K.B. (2020) Medical Waste-Sorting and Management Practices in Five Hospitals in Ghana. Journal of Environmental and Public Health, 2020, Article ID: 2934296. https://doi.org/10.1155/2020/2934296

[9] Awodele, O., Adewoye, A.A. and Oparah, A.C. (2016) Assessment of Medical Waste Management in Seven Hospitals in Lagos, Nigeria. BMC Public Health, 16, Article No. 269. https://doi.org/10.1186/s12889-016-2916-1

[10] Mohammed, S., Othman, N., Hussein, A. and Rashid, K. (2017) Knowledge, Attitude and Practice of Health Care Workers in Sulaimani Health Facilities in Relation to Medical Waste Management. Kurdistan Journal of Applied Research (KJAR), 2, 143-150. https://doi.org/10.24017/science.2017.2.21

[11] Gao, Q., Shi, Y., Mo, D., Nie, J., Yang, M., Rozelle, S. and Sylvia, S. (2018) Medical Waste Management in Three Areas of Rural China. PLOS ONE, 13, e0200889. https://doi.org/10.1371/journal.pone.0200889

[12] Eker, H.H. and Bilgili, M.S. (2011) Statistical Analysis of Waste Generation in Healthcare Services: A Case Study. Waste Management \& Research, 29, 791-796. https://doi.org/10.1177/0734242X10396755

[13] World Health Organization (WHO) (2014) Safe Management of Wastes from Health-Care Activities.

https://apps.who.int/iris/bitstream/handle/10665/85349/9789241548564 eng.pdf;jse ssionid=944269B3D09EE50E6C2696A314C9E79D? sequence $=1$

[14] Jang, Y., Lee, C., Yoon, O.S. and Kim, H. (2006) Medical Waste Management in Korea. Journal of Environmental Management, 80, 107-115.

[15] Novi, F., Enri, D., Indah, R., Venny, U. and Yati, S. (2018) Generation and Proportion Assessment of Hospitals Infectious Waste in Bandung Region Indonesia. E3S Web of Conferences, 73, 07018. https://doi.org/10.1051/e3sconf/20187307018

[16] Korkut, E.N. (2018) Estimations and Analysis of Medical Waste Amounts in the City of Istanbul and Proposing a New Approach for the Estimation of Future Medical Waste Amounts. Waste Management, 81, 168-176.

https://doi.org/10.1016/j.wasman.2018.10.004

[17] Pandey, A., Ahuja, S., Madan, M. and Asthana, A.K. (2016) Bio-Medical Waste 
Management in a Tertiary Care Hospital: An Overview. Journal of Clinical and Diagnostic Research, 10, DC01-DC03. https://doi.org/10.7860/JCDR/2016/22595.8822

[18] Singh, Z., Bhalwar, R., Jayaram, J. and Tilak, V.W. (2001) An Introduction to Essentials of Bio-Medical Waste Management. Medical Journal Armed Forces India, 57, 144-147. https://doi.org/10.1016/S0377-1237(01)80136-2

[19] Chandrappa, R. and Das, D.B. (2012) Chapter 6: Biomedical Waste. In: Solid Waste Management, Springer, Berlin, Heidelberg, 147-175. https://doi.org/10.1007/978-3-642-28681-0 6

[20] Hamoda, H.M. El-Tomi, H.N. and Bahman, Q.Y. (2005) Variations in Hospital Waste Quantities and Generation Rates. Journal of Environmental Science and Health, 40, 467-476. https://doi.org/10.1081/ESE-200045650

[21] Sartaj, M. and Arabgol, R. (2015) Assessment of Healthcare Waste Management Practices and Associated Problems in Isfahan Province (Iran). Journal of Material Cycles and Waste Management, 17, 99-106.

https://doi.org/10.1007/s10163-014-0230-5

[22] Deneke, I., Aqiel, M., Desalegn, B. and Atsbeha, H. (2011) Assessing the Management of Healthcare Waste in Hawassa City, Ethiopia. Waste Management \& Research, 29, 854-862. 